\title{
Multimodal Representational Meanings of ISIS's Victims on Facebook
}

\author{
Hamid TaradLafta, Hanita Hassan, Farah Abdul Jabbar Al Manaseer
}

\begin{abstract}
After 2003, Iraq faced different terrorist groups that committed massacres against the Iraqis. They presented their violence in media using social networks and particularly Facebook posts. This article investigates the representation of Islamic State in Iraq and Syria's portrayal of three images posted on Facebook posts. The article focuses on the representational meanings using Kress and Van Leeuwen's (2006) model as an analytical framework and the discussion focuses on narrative processes. The findings of the current study highlight the effective role played by images in the process of meaning-making by means of narrating the concept of Islamic State in Iraq and Syria style and to portray their ideology through disseminating the message of fear and intimidating.
\end{abstract}

Keywords: multimodal discourse analysis, Facebook, ISIS, representational meanings, visual images.

\section{INTRODUCTION}

The role of the non-verbal resources, like sound, images, and colors is not limited to entertain and clarify but somewhat it goes beyond that to play a significant role in sending different social, educational, economic and even political messages [1]. More specifically, these paralanguage features carry out diverse functions when combining and incorporating linguistic discourse[2]. Social media, in recent times, play a key role in our life [3]. Thus, the excessive use of such platforms, like Facebook become epidemic from one side and remarkable in people's lives and luxury from another side [4]. According to Friedland[5], ISIS is the first radical group to systemically exploit the imaginative capacities of social media. Led by Abu Baqr al-Baghdadi, ISIS is a political and military organization based in Syria and Iraq that adheres to a thorough interpretation of Islam as a political philosophy.

As stated by Ben-Yahuda[6], ISIS is aimed at creating goal-oriented feelings of anxiety and fear among its targets which ease the road for ISIS goals attainment. Terror can assume many material forms and is fundamentally the generation of fear either by using direct violence or by a credible threat to use it. Violence can be either verbal or physical, with intimidation as part and parcel of it. Terrorist groups generally recognized the potentials, importance, and usage of social networking all around the world.

\section{Revised Manuscript Received on October15, 2019}

Hamid TarradLafta,Language Academy, Faculty of Social Sciences and Humanities, UniversitiTeknologi Malaysia, JB. Email: htarad@uowasit.edu.iq

Hanita Hassan*, Language Academy, Faculty of Social Sciences and Humanities, UniversitiTeknologi Malaysia. Johor Bahru, Malaysia, Email: hanita@utm.my

Farah Abdul Jabbar Al Manasser, Department of English Language and Literature, Al-Munstansiriyah University, Baghdad, Iraq. Email: farah_fa78@yahoo.com
As a consequence, social media platforms like Facebook, Instagram, Twitter, YouTube have turned into a theatre for such organizations through an active account which represents the actual exploiting of the social network service to frighten people [7]. In addition, the media have open access and hence a good source of spreading ideologies especially hatred and radicalization. The agenda-setting goals are achieved easily through the media platforms especially Facebook is an example of well established social media used to disseminate the ideology of fear and killing [8] Manifesting their un-tolerated actions is well planned since the aim is to createpanicamong people and this can be fulfilled through using verbal and non-verbal multimodal modes.

\section{MULTIMODAL DISCOURSE ANALYSIS OF FACEBOOK'S POSTS}

Basically, linguistics is approached by systemic-Functional Linguistics which sees language as a set of choices and a social semiotic system [9]. Moreover, language consists of three concurrent metafunctions namely, textual function, interpersonal function and ideational function [10]. The analysis of multilmodal discourse as a multidisciplinary research area provides a significant analytical framework that is meaningful due to the interaction of a range of semiotic resources such as language, image, gesture, sound, page design and site design [11].Multimodal discourse analysis (MDA)simply means studying the overlapping and correlation of different types of modalities of communication within a specified context [12]. Thus, the main concern of MDA is how these effective tools complementing one another in the making of meaning [13], [35]. As far as the current article is concerned, the focus is mainly to discuss the represented meaningsof ISIS's victim images posted on Facebook and identifying the ISIS ideologies portrayed through the images.

According to Muller and Sawitzki [14] what image describes cannot be described in words, hence words can provide a gloss with the semiotic modes of writing and of the images aredistinguished in what they permit, that is, in their affordances. The role of visuals like pictures in communication has become very prominent due to the advent of digital communication technologies and this justifies why social network users try to choose easily digestible content and share lots of images to draw attention [15-17] Accordingly, it is essential to analyze the function of visual images to give meaning to speech. In the process of multimodal text analysis, the criteria will be which modes like spoken words, images, music, written text, and movement and transitions, in relation to each other, will be the focus of the analysis [18].

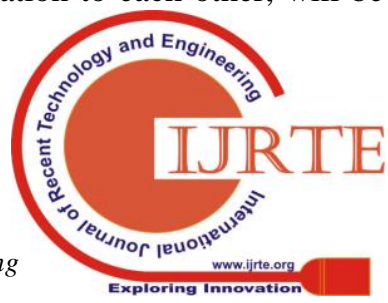


The multimodal text analysis seeks to systematically describe non-linguistic resources, as well as the significant interaction of verbal, visual and audio data.

Kress G. \& Van Leeuwen [19] believe that analyzing visual communication is a crucial and fundamental part of the critical discipline. They see that critical discourse analysis is not only restricted to language in the verbal texts to realize meaning but also it combines parts of verbal texts with other semiotic modes such as pictures, colors, and typography to realize the meaning. Kress G. \& Van Leeuwen[19] build their social semiotic approach on Halliday's idea of the grammar of the semiotic modes (Systemic Functional Grammar) to study visual images. To analyze any human communication system, Halliday realizes that any language sign contains three metafunctions relevant to study language: ideational function, interpersonal function, and textual function. Kress and Van Leeuwen developed these three metafunctions and expanded their study on discourse to include visual images. They believe that visual design is similar to all kinds of semiotic modes and similar to language. It can be used to fulfill three metafunctions.

They are representational meaning, interactive meaning, and compositional meaning which are applied to visual images. As stated by (Kress G. \& Van Leeuwen, 2006, p. 42) that representational meaning refers to "any semiotic mode has to be able to describe features of the world as it is experienced by humans." That means the objects or elements and their relations in the world can be represented outside the representational system by any semiotic mode. The elements or objects that are found in visual images are called participants. They may be people, place, or things of different types of semiotic modes which are represented in or by images [20]. Each semiotic act contains two categories of participants which are interactive participants refer to "the participants who speak and listen, write and read, make images or view them." The second type is represented participants refer to participants who are the subject matter of the communication. As stated by Kress and Van Leeuwen [19], representational meanings can be classified into two types; narrative representations and conceptual representations. However, the focus of this paper is on the narrative representation.

Narrative representation states the way in which the participants are linked by a vector. They are characterized as making or doing something to or for each other. Narrative patterns focus on interpreting "unfolding actions and events, manners of change, temporary spatial arrangements." [19]. On the basis of the kinds of the vector and the numbers and the kinds of the participants included, there are twotypes of narrative processes which are action and reaction[19]. In action process, if there is one participant from which vector departs is called "Actor" and the process is called "non-transactional" because there is no "Goal" which is the participant "at whom or which the vector is directed and to whom or which the action is done or aimed". While if there are two participants, one of them is an actor and the other is the goal, so the process is transactional [20].

The process is reactional when the vector is composed by an eye- line, or "by the direction of the glance of one or more of the represented participants." There are two participants. One of them is named "Reactor, the participant who does the looking must be a human or a human-like animal." While the second is named Phenomenon, the participant at whom or which the reactor is looking." [20]. Speech and mental processes appear in comic strips by using a special kind of vector. They are designed by "the oblique protrusions of thought balloons and dialogue balloons that link drawings of speakers or thinkers to their speech or thought." [19]. Narrative processes may consist of participants in the form of other means of vectors instead of vectors. This is known as circumstances. They are the participants who could be deleted without affecting the main idea realized by the narrative processes but may lose some information. Circumstances are classified into three types: setting (locative circumstances), means (tools), and accompaniment [19].

\section{IDEOLOGY AND LANGUAGE}

According to Atkinson [22], the usage of language mainly focuses on the use of speech kits in order "to represent a specific discourse community or a group of belief links". Language users are undoubtedly defined as members of a community, group, or organization, and assume to speak, write, or understand from a particular social status. Ideological analysis inspects which ideologies are regularly related to this position, like the position usually protected or legitimated by discourse. The basic idea of ideological discourse analysis is not simply to find out essential ideologies but to systematically relate structures of discourse with structures of ideologies [21],[23]. According to Van Dijk[24], a key idea in ideology is both the use/abuse of language, which includes multidisciplinary or interdisciplinary approaches involving many features and dimensions, like social and cognitive factors.

Generally speaking, ideology is both a belief system and an idea that needs a cognitive element that has the ability to account properly for equally the notions of beliefs and belief systems. These belief structures are communally shared by the members of a collection of social actors [27]. Van Dijk[23] stated that essential believe that discourse analysis is an ideology analysis because "ideology is usually, "but not only express and reproduce in discourse and communication." His method of ideology analysis has three parts: social analysis, cognitive analysis, and discourse analysis. For Van Dijk, social cognition and personal cognition are between society and discourse. He defines social cognition as a "psychological representation system and group member process." In this sense, for Van Dijk [21] states that "ideology is a global and abstract psychological system, therefore, ideology" indirectly affects the individual cognition of group members " Ideologies, in other words, "indirectly influence the personal cognition of group members" in their act of comprehension of discourse among other actions and interactions [23].

Ideology is well-defined as a procedure of social cognition, and more precisely, the elementary beliefs that set up the social representation of social groups. The meaning of speech is not constrained to the meaning of its words and sentences. In the same way, the discourse has additional "universal" meanings, such as 'topics' or 'themes'. In the analysis of ideological discourse, the meaning of inferring sentences or text fragments is obvious and can be an influential critical research tool. Ideologies often emerge when two or more groups have conflicting interests when there is social struggle or competition, and in the situation of domination [28]. Ideology affects discourse systems like (formatting, 
choice of imagery, placing of the story in the newspaper, syntactic choices - active/passive) and meanings [29, 30]. According to Van Dijk [30] ideology is a relatively unchanging system that focuses on critical beliefs rather than individual ideas, providing tools at multiple levels of discourse, text, and speech, and for ideologies that will develop, confirm, change, and sustain. "A major feature of the ideological structure found in the discourse, "the polarization of ideology between internal and external groups."

\section{OBJECTIVES}

The objectives of the current study are thus:

1. to investigate the representational meaningsof ISIS images posted on Facebook through Multimodal discourse analysis approach (MDA).

2. to analyse the ideologies of ISIS portrayedby means of selected images.

\section{METHODOLOGY}

The current study is a qualitative study of which the data were collected from Facebook postings. Images of ISIS's victims ofthree different groups which are the Camp Speicher massacre, the Yazidi woman and a young Iraqi civilian were analysed using multimodal discourse approach (MDA) as introduced by Kress and Van Leeuwen [19]. Practically, three images involving three different topics are selected (the camp Speicher massacre on 12 June 2014, the Yazidi woman on 2 August 2014 and the young Iraqi civilian. The aimsof the analysis were, firstly, to investigate the representational meanings of the images, that is, how the victims were represented and secondly, to determine the ideologies of ISIS.Using narrative representation as the analytical framework, the participants of the images were first determined and the participants can be people, things or places. Actor and goals were then identified and the representation of these participants is the tool for meaning-making, of which means readers can grasp the meaning of what happened through the participant representations. In addition, the representation of participants is also used to portray the ideologies of ISIS.

\section{FINDINGS}

The Representational meaning of Figure 1 aredepicted by means of different participants, for example, ISIS members, Iraqi Air Force cadet, the place that is President palace in Tikrit, North of Iraq, and finally things like Handguns (pistol and rifle), ISIS's flag, barbed wire and blood. The process is narrative due to the existence of a vector line between the actor, who is the ISIS's members, and the goal, who is the Iraqi Air Force cadet. It is clear that the execution is the action process, of which ISIS's member is shown pointing a gun towards the Iraqi Air Force cadet. The reaction process, on the other hand,is from the Iraqi Air Force cadet, who is helpless and trying to free himself up, towards the ISIS's members.

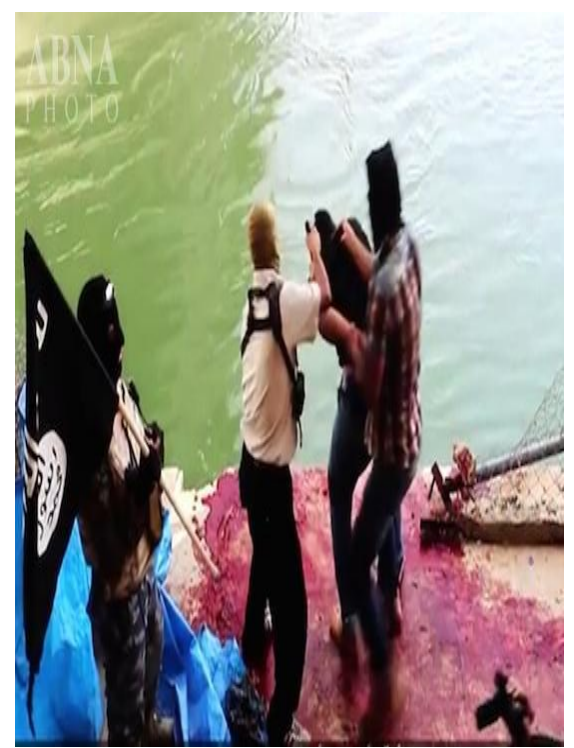

Fig.1. Execution ofIraqi Air Force cadet

It is one of the most frightful of many cruel videos disseminated by the ISIS group on social media platforms like Facebook, of which showing the executing process of their victims. This act is part of the massacre which took place in Camp Speicher on June 12, 2014, when the Islamic State executed more than 1,700 new recruits at the previous Saddam Hussein President Palace on the banks of the Tigris River near Tikrit. Tens of young men were videotaped being driven by force at execution point by masked ISIS gunmen who wore black uniform towards mass graves which was full with dead bodies. The victims could therefore see the mass grave before they were killed. Others are beaten harshly as they stumble down stone steps in groups onto a small dock covered with blood under a bridge on the Tigris. As each one was dragged frontward by an ISIS member, he was shot in the head by a man with a pistol and before he dropped into the water [31].

Similar to Figure 1, there are various participants that are used to disseminate the representational meaning of image in Figure 2. The participants are people, represented by ISIS members, the Yazidi woman;place, for example,the main street or public place; and thing, which are depicted by a metal chain, cane, loud-hailer, and black clothes. It's clear that the process type is a narrative process due to the abundance of vector lines. The main action process is triggered from the ISIS member towards the Yazidi woman. The image shows an auction process which was taking place, in which the captured woman was sold as a sex-slave since she was not a Muslim (Spaya). And, the reaction process, on the other hand, is from the Yazidi woman, who are helpless and could not afford to free herself, towards the ISIS's members 


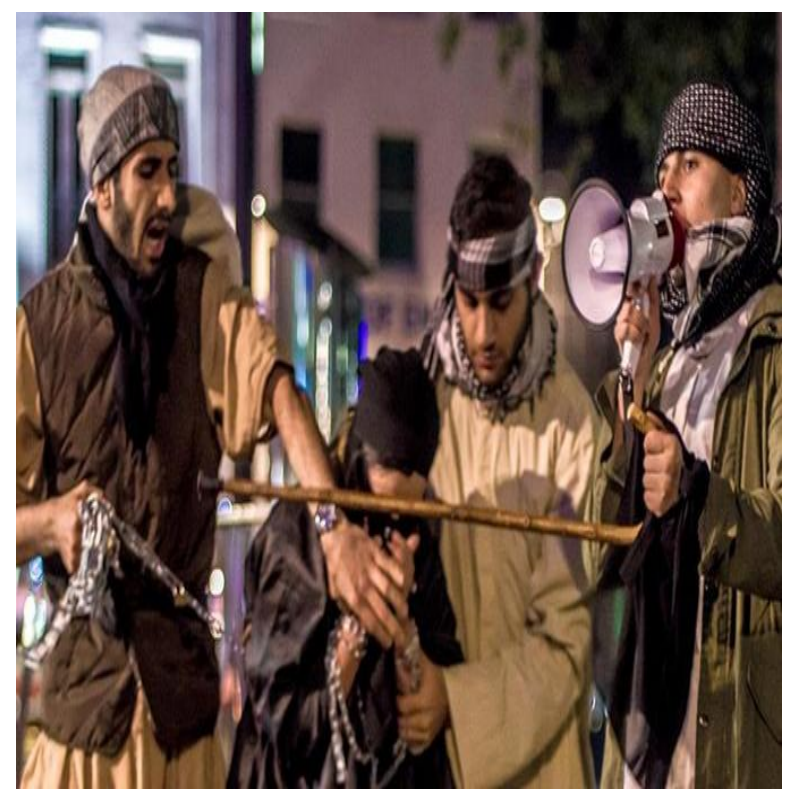

Fig.2. A Yazidi woman for sale (Auction of Sex-slaves)

Yazidis are a religious minority in northern Iraq and are regarded by the Islamic State as a "devil worshipper" who distrusts god [32]. Rape, slavery, and human trading are used against people whom ISIS considers to be pagan (for example, Yazidis) and have become so ubiquitous that the bureaucracy has been established for the sale of sexual slaves [33][26].

Participants in Figure 3 are ISIS's members and an Iraqi civilian, a main street in Al Mosul city and variousthingsare depicted, for example, sharp knives, white rope, table, chairs, and black and Khaki outfits. Similar to Figures 1 and 2, the process type is a narrative process, of which the actors are ISIS members and the goal is the Iraqi civilian who was going through an amputation process. The reactional process is represented by the Iraqi civilian who refused to be amputated, by which his right hand would be cut off. Another reaction process found is portrayed through a vector line fromthe crowd, who were witnessing the process of amputation.

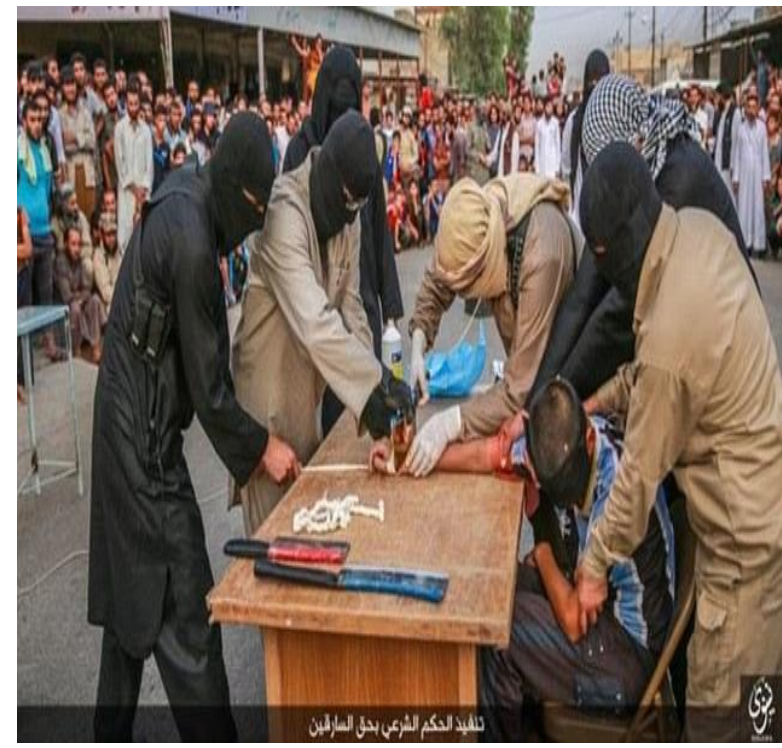

Fig.3. Public amputation punishment
Today, the Islamic State, as the de facto government, has issued a document for Nineveh civilians as a "city contract" that covers 16 annotations, by which it was clearly stated that public amputation is a punishment for stealing[34].

The findings of this study clearly show that the intended messages are depicted through the representation of people, things and place as participants in the images.In other words, through the participants and with the combination of contextual information, viewers are able to make meaning of the intended message. This thus suggests that the images uploaded on the Facebook are not simple any images but the images should be able to help viewers decipher what is being communicated.

\section{DISCUSSION}

The representational metafunction of semiotic patterns or modes offers an assortment of options during which people, objects, places, and ideas can be represented and related to each other. Hence, representational meanings can be divided into two groups: participants and carriers (i) Represented participants are those who constitute the core of the communication and could be categorized as individuals or groups that determine exclusivity or pluralism, cultural, biological or a combination of the two. Cultural categorization includes attributes such as clothing and hairstyle. Biological attributes can be used to create ethnic stereotypes (ii) Represented carriers focus on the person who is the carrier and the attributes are what create the meaning [19].

Moreover, represented participants (RPs) in the data of this study show people are represented by various groups of people, for example, ISIS members, an Iraqi Air Force cadet, Iraqi civilian and a Yazidi woman. Place, on the other hand, is represented by a concrete stage as a crime scene/ theatre, covered with blood on Tigris river in Iraq as shown in Figure 1 , and public place seems to be a city center or main street as in Figures 2 and 3. Finally, things are represented by blood spot on the ground, handguns such as a pistol and rifle, ISIS flag, barbed wire, metal and blue plastic represented by a metal chain, cane, black clothes which imposed on non-Muslims and hailer, whilst, things in Figure 3 are represented by Sharp knives, white rope, table, chair, and the black and Khaki outfits. The connotation of the visual imagesposted by ISIS on Facebook is apparently meant violence. It seems they donot hesitate to kill anyone, anywhere despite the citizenship and religious beliefs in order to spread the message of fear around the world. In addition, even the religious minorities in Iraq like Yazidi community as shown in Figure 2 could not escape from the unjust oppression of ISIS. It is apparent how the Yazidi women were mistreated through the chain of iron stalked, caning at the slave market and sold as sex-slaves.Figure 3 indicates ISIS is implementing the Islamic Sharia (Law) against the thieves in Al Musol city, instead of handing the thief to the police for legal action and put him in the prison, they conduct amputation as public punishment.

As mentioned earlier, an image can be classified as a narrative or conceptual based on the existence of a vector line. Narrative is when there is a vector line, otherwise it is a conceptual and there are two types of conceptual process, which are

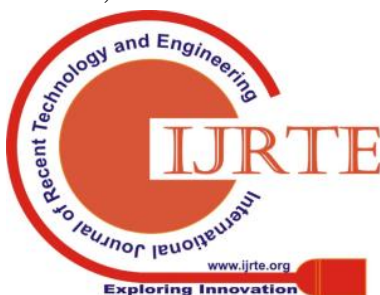


classification and symbolic [19]. So a vector which is a line, or implied line, that proposes direction formed by a depicted element or an arrow, departing from a participant, i.e. Actor [19]. Vectors in Figure 1 are represented by the gaze or glance of ISIS members and the handgun direction towards the victim. Nevertheless, there is no vector line from the opposite direction, that is, from the victim towards the ISIS members because his head was pressed down to enable the ISIS gunman to shoot him on the head and therefore he could only look down on the ground. Similarly, there are various vector lines found in Figure 2, for example,the gaze or glanceof the ISIS member who is holding the metal chain towards his friend who is using hailer, handdirection of the ISIS member towards the victim, the metal chain that connects the ISIS member and the victim and again the victim who is the Yazidi woman is looking down, by which there is no eye contactbetween the Yazidi woman and ISIS's members. The vector lines in Figure 3 are formed by the sharp knife which is used for amputation, eye line from the ISIS man who is cutting off the victim's hand and the men holding the victim, and the gaze from the crowd towards the ISIS members and the victim.

There are two types of action: transactional which consists of Actor and Goal) and non-transactional which has only Actor without Goal. Actor is the member from which the vector comes, or from which a vector departs or which itself, in whole or in part, forms the vector [19]. In Figures 1 and 2, it is apparent that the Actors are the ISIS members who are looking towards the victims, of which signifies that goals are always the victims. The goal in Figure 1 is the Iraqi Air Force cade and in Figure 2 is the Yazidi woman. Figure 3, on the other hand, consists more than one Actor, besides the ISIS members as Actor, the crowd is also represented as Actor looking towards the ISIS members and victim. This clearly suggests that images posted on ISIS Facebook have the ISIS member as Actor their victims are depicted as Goal. The intended message is to inform others of what they are capable of doing. Therefore, all the images analysed in this study have narrative process with transactional action, of which they have ISIS men and audience as Actor and their victims as Goal. However there is also non-transactional action which is formed by the eye vector of ISIS members towards something which is not in the image, in other words, there is no Goal. This is to say that the perception is directed towards another participant or phenomenon which is not found in the image[19].

A secondary participant in multimodal analysis is called Circumstance. Circumstance in a narrative process is expressed by means of other visual elements which are used to depict location, tools and accompaniment and they are not connected through any vector line. There are three types of circumstance in visual images, and the types are Location (associated with the participants in the setting), Means (presentation of tools used in action processes) and Accompaniment (perception of the participants, not connected by a vector)[19]. As can be seen in Figure 1, the encoding of reality is made more detailed by using circumstances of location (the setting against which the ISIS's members and the Iraqi Air Force cadet are placed) and means (the handguns). Similarly, the encoding of reality in Figure 2 is made more detailed by using Circumstance of Location (the setting against which the ISIS's members and the Yazid woman are placed) and Means (the metal chain, hailer and cane as representations of slavery).

Basic ideology is the root of verbal content that matches the visual aspects of ISIS communication, and ISIS communication is widely regarded as violence to create fear and anger. In addition, the images portray the ideology of ISIS that is drawing a clear border between Us and Them, if you are not one of Us you are do not deserve to be treated well[25]. The ideology of ISIS can be described as inclusive and at the same time incompatible with free public dominion ideas, competitive cultural terrain, political pluralism and social variety[26].

\section{CONCLUSION}

Using the visual grammar of Kress and Van Leeuwen (2006), three ISIS images posted on Facebook were analyzed from the point of view of representational meaning. The characteristics of the three images were rational or reasonable, rich in detail, objective and realistic, and reflected the concerns, aspects, ideology, and propaganda of ISIS. The ISIS organization prefers to use violence in portraying his crimes against innocent citizens. Accordingly, the images published by ISIS on Facebook seem to have been well documented by a high-resolution process and were created on the basis of prominent images. Therefore, ISIS creates a typical environment for influence, interaction or fear and aversion with its victims or viewers. Besides, the focus on filming violent scenes of beheading and killings is determined decisively and has more forceful consequences because here, in ISIS's postings, images are very detailed. And this was creatively used by ISIS for two reasons; first, to brainwash viewers of their ideology thatcan be seen as recruiting new jihadists, and secondly, to intimidate or create fear among opponents and escalate panic and overestimate their fears towards ISIS.

\section{REFERENCES}

1. Liu, J., Visual Images Interpretive Strategies in Multimodal Texts. Journal of Language Teaching \& Research, 2013. 4(6).

2. Duncum, P., Visual culture isn't just visual: Multiliteracy, multimodality and meaning. Studies in art education, 2004. 45(3): p. 252-264

3. Wells, W., Social media and social networking: What's the difference? Available online. 2011

4. Pornsakulvanich, V., Excessive use of Facebook: The influence of self-monitoring and Facebook usage on social support. Kasetsart Journal of Social Sciences, 2017.

5. Friedland, E., Special Report: The Islamic State. The Clarion Project, 2015(s 14).

6. Ben-Yehuda, N., Terror, media, and moral boundaries. International journal of comparative sociology, 2005. 46(1-2): p. 33-53.

7. Weimann, G., Terror on the Internet: The new arena, the new challenges. 2006: US Institute of Peace Press.

8. Awan, A.N., Virtual jihadist media: Function, legitimacy and radicalizing efficacy. European Journal of Cultural Studies, 2007. 10(3): p. 389-408.

9. Halliday, M.A., 2000. An introduction to functional grammar, 1994

10. Halliday, M.A., Language as social semiotic. London, 1978.

11. Tan, S., et al., A multimodal mixed methods approach for examining recontextualisation patterns of violent extremist images in online media. Discourse, Context \& Media, 2018. 21: p. 18-35.

12. Snyder, J., Applying multimodal discourse analysis to the study of image-enabled communication. 2010.

13. Matthiessen, C., The multimodal page: A systemic functional exploration. New directions in the analysis of multimodal discourse, 2007: p. 1-62. 
14. Muller, D.W. and G. Sawitzki, Excess Mass Estimates and Tests for Multimodality. Journal of the American Statistical Association, 1991. 86(415): p. 738-746.

15. Alper, M., War on Instagram: Framing conflict photojournalism with mobile photography apps. New Media \& Society, 2014. 16(8): $\mathrm{p}$ 1233-1248.

16. Seo, H., Visual propaganda in the age of social media: An empirical analysis of Twitter images during the 2012 Israeli-Hamas conflict. Visual Communication Quarterly, 2014. 21(3): p. 150-161.

17. Yang, J. and Y. Zhang, Representation Meaning of Multimodal Discourse-A Case Study of English Editorials in The Economist. Theory and Practice in Language Studies, 2014. 4(12): p. 2564.

18. Oddo, J., Discourse-based methods across texts and semiotic modes: Three tools for micro-rhetorical analysis. Written Communication, 2013. 30(3): p. 236-275.

19. Kress G. \& Van Leeuwen, Reading Images: The Grammar of Visual Design 2006, London: Routledge.

20. Yang, J. and Y. Zhang, Representation Meaning of Multimodal Discourse--A Case Study of English Editorials in The Economist. Theory \& Practice in Language Studies, 2014. 4(12).

21. Yang, Y., A social semiotic approach to multimodal discourse of the badge of Xi'an Jiaotong University. Theory and Practice in Language Studies, 2016. 6(8): p. 1596-1601.

22. Atkinson, T.N., Textual mapping of imitation and intertextuality in college and university mission statements: A new institutional perspective. Semiotica, 2008. 2008(172): p. 361-387.

23. Van Dijk, T.A. Ideological discourse analysis. in In. 1995. Citeseer

24. Van Dijk, T.A., Ideology: A multidisciplinary approach. 1998: Sage.

25. Gareth, T., Extremes of Engagement: The post-classical public relations of the Islamic State. Public Relations Review, 2017. 43(5): p 915-924.

26. Gerges, F.A., Isis: A History. 2017: Princeton University Press.

27. Bloor, M. and T. Bloor, The practice of critical discourse analysis: An introduction. 2013: Routledge.

28. Van Dijk, T.A., Ideology and discourse: A multidisciplinary introduction. Pompeu Fabra University, Barcelona, 2000: p. 1025-1034.

29. Moore, K., P. Mason, and J.M.W. Lewis, Images of Islam in the UK: The representation of British Muslims in the national print news media 2000-2008. 2008.

30. Van Dijk, T.A., Ideology and discourse analysis. Journal of Political Ideologies, 2006. 11(2): p. 115-140.

31. Patrick Cockburn. Camp Speicher massacre: Retracing the steps of Isis's worst-ever atrocity. INDEPENDENT 2017; Available from https://www.independent.co.uk/news/world/middle-east/camp-speiche r-massacre-isis-islamic-state-tikrit-air-academy-iraq-a8040576.html.

32. El-Masri, S., Prosecuting ISIS for the sexual slavery of the Yazidi women and girls. The International Journal of Human Rights, 2018. 22(8): p. 1047-1066.

33. Lister, C.R., The Islamic State: A Brief Introduction. 2015: Brookings Institution Press.

34. Julian Robinnson. ISIS amputate the hands of two boys aged ten and 12 who refused to execute two civilians in front of their families in Mosul. 2017; Available from: https://www.dailymail.co.uk/news/article-4184950/ISIS-chop-hands-b oys-not-executing-prisoners.html.

35. Hassan, H. 2012. Multimodal Communication of Corporate Website Designs. Skudai: UTM Press.

\section{AUTHORS PROFILE}

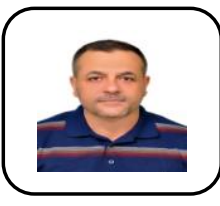

Hamid TaradLafta is a Ph.D. scholar at language Academy, Faculty of Social Science and Humanities. a member of PGSS and PGSS. Academic staff in Wasit University-Iraq.His research interests include Systemic Functional Linguistics (SFL), multimodality, discourse analysis, Ideology and

CDA.

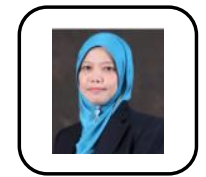

Associate Professor Dr. Hanita Hassan is a lecturer at Language Academy, UTM and she is currently the Head ofLanguage and Communication in Society (LCS) research group. She has written several books, among others includeMultimodal Communication of Corporate Website Design, New Perspectives in Language and Communication Research and English for Career Search. Her book on Multimodal Communication of Corporate Website Design won the Original Book Award, UTM in 2012. Her research interests include Systemic Functional Linguistics (SFL), multimodal discourse, and ELT methodology.

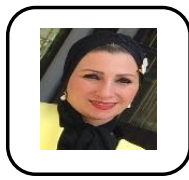

CDA.
Associate Professor Dr. Farah Abdul-Jabba Al-Manaseer department of English language and literature, AL-Mustansiriyah University, Baghdad. Her research interests include Systemic Functional Linguistics (SFL), multimodality, discourse analysis, and 